\title{
Non-COVID Neurological Emergencies: A Silent Killer Going Unnoticed during COVID-19 Pandemic
}

\author{
Nikita Dhar ${ }^{1, *}$ Govind Madhaw ${ }^{1, *} \quad$ Mritunjai Kumar ${ }^{1} \quad$ Niraj Kumar ${ }^{1, \odot ~} \quad$ Ashutosh Tiwari ${ }^{1}$ \\ Vinayak Jatale ${ }^{1}$ \\ ${ }^{1}$ Department of Neurology, All India Institute of Medical Sciences, \\ Rishikesh, Uttarakhand, India

\begin{abstract}
Address for correspondence Niraj Kumar, MD, DM, Department of Neurology, All India Institute of Medical Sciences, Rishikesh, Uttarakhand 249203, India

(e-mail: drnirajkumarsingh@gmail.com).
\end{abstract}

J Neurosci Rural Pract 2021;12:461-469.

\begin{abstract}
Objective This study assesses the impact of coronavirus disease 2019 (COVID-19) on the pattern of neurological emergencies reaching a tertiary care center.

Materials and Methods This is a retrospective and single center study involving 295 patients with neurological emergencies mainly including acute stroke, status epilepticus (SE), and tubercular meningitis visiting emergency department (ED) from January 1 to April 30, 2020 and divided into pre- and during lockdown, the latter starting from March 25 onward. The primary outcome was number of neurological emergencies visiting ED per week in both periods. Secondary outcomes included disease severity at admission, need for mechanical ventilation (MV), delay in hospitalization, in-hospital mortality, and reasons for poor compliance to ongoing treatment multivariate binary logistic regression was used to find independent predictors of in-hospital mortality which included variables with $p<0.1$ on univariate analysis. Structural break in the time series analysis was done by using Chow test.

Results There was $53.8 \%$ reduction in number of neurological emergencies visiting ED during lockdown (22.1 visits vs. 10.2 visits per week, $p=0.001)$, significantly affecting rural population $(p=0.004)$. Presenting patients had comparatively severe illness with increased requirement of MV $(p<0.001)$ and significant delay in hospitalization during lockdown $(p<0.001)$. Poor compliance to ongoing therapy increased

Keywords

- COVID-19

- lockdown

- stroke

- status epilepticus

- meningitis

- neurological emergencies

from $34.4 \%$ in pre-lockdown to $64.7 \%$ patients during lockdown $(p<0.001)$, mostly due to nonavailability of drugs $(p<0.001)$. Overall, 35 deaths were recorded, with $20(8.2 \%)$ in pre-lockdown and $15(29.4 \%)$ during lockdown $(p=0.001)$. Lockdown, nonavailability of local health care, delay in hospitalization, severity at admission, and need for MV emerged as independent predictors of poor outcome in stroke and delay in hospitalization in SE.

Conclusion COVID-19 pandemic and associated lockdown resulted in marked decline in non-COVID neurological emergencies reporting to ED, with more severe presentations and significant delay from onset of symptoms to hospitalization.
\end{abstract}

* These authors contributed equally to the article.

published online

February 22, 2021
DoI https://doi.org/

$10.1055 / \mathrm{s}-0040-1722810$ ISSN 0976-3147.
(C) 2021. Association for Helping Neurosurgical Sick People.

This is an open access article published by Thieme under the terms of the Creative Commons Attribution-NonDerivative-NonCommercial-License, permitting copying and reproduction so long as the original work is given appropriate credit. Contents may not be used for commercial purposes, or adapted, remixed, transformed or built upon. (https://creativecommons.org/licenses/by-nc-nd/4.0/).

Thieme Medical and Scientific Publishers Pvt. Ltd. A-12, 2nd Floor,

Sector 2, Noida-201301 UP, India 


\section{Introduction}

The severe acute respiratory syndrome coronavirus 2 (SARS-CoV-2) infection, resulting in coronavirus disease 2019 (COVID-19), has emerged as a major public health concern due to its high human-to-human transmissibility manifesting as large-scale community-based outbreak across various nations. It was labeled as a global pandemic on March 11, 2020 by World health organization, ${ }^{1}$ and our health care sector has been at the epicenter of this unprecedented health emergency. The first case of COVID-19 was reported in India on January 30, 2020 in Kerala, ${ }^{2}$ and by the end of 3rd week in March, the number of COVID-19 cases showed a significant rising trend, and Indian Government imposed a complete national lockdown to prevent its rapid spread and prepare the health care system. A complete lockdown meant closure of all regular out-patient departments and elective surgeries across the entire nation of 1,300 million population, leaving the hospitals open for only medical and surgical emergencies. However, the resulting home confinement along with limitation of transport facilities due to lockdown and possible disruption in pharmaceutical supply chain meant a significant challenge for patients to access essential health care services.

On the other hand, as the entire health care system started preparation in anticipation of the worst possible scenario of the pandemic, the manpower and essential equipment meant for specialized care including neurological emergencies were diverted toward COVID-19 patients care. A recent multicenter study reported nearly two-thirds reduction in emergency visits of patients with acute stroke and those receiving intravenous thrombolysis in selected apex centers across India during lockdown. ${ }^{3}$ The aim of our study was to understand the effect of nationwide lockdown on non-COVID neurological emergencies attending our emergency department (ED), for which we compared the pattern of patients and their outcome at discharge reaching before and during lockdown periods. In addition, we assessed the hurdles faced by such patients to access health care facilities including drug availability, local health care (LHC) facilities, and emergency transport services. Our study will help improve patient care with judicious use of available manpower and resources, without risking lives of patients or health care workers.

\section{Materials and Methods}

This study involves a retrospective chart review of patients, aged 18 years or above, with neurological emergencies, including acute stroke, ${ }^{4}$ status epilepticus $(\mathrm{SE}),{ }^{5}$ meningitis, ${ }^{6,7}$ encephalitis, ${ }^{6}$ acute inflammatory demyelinating polyneuropathy, ${ }^{8,9}$ and myasthenic crisis, ${ }^{10}$ visiting ED at All India Institute of Medical Sciences Rishikesh, Uttarakhand, India, from January 1 to April 30, 2020. The 4-month period included a pre-lockdown period from January 1 to March 24, 2020 followed by a lockdown period from March 25 to April 30, 2020. In-hospital neurological emergencies in non-neurological admissions were excluded. The project was approved by the institutional ethics committee.

\section{Data Extraction}

For each patient, medical records were reviewed and following parameters were extracted: demographic profile, including age and sex, residential address, diagnosis, delay in hospitalization, reason for delay, and poor drug compliance, if reported. As per the medical records, each patient was examined by the neurology team including a neurology consultant. Neurological examination included assessment of sensorium by Glasgow Coma scale (GCS), muscle power, sensory system examination with deep tendon reflexes, and limb incoordination. The admission disability was assessed on the basis of respective scales including Hughes Disability Scale ${ }^{11}$ for Guillain-Barre syndrome (-Supplementary Table S1 [available in online version]), Myasthenia Gravis Functional Assessment ${ }^{12}$ score (-Supplementary Table S2 [available in online version]), National Institutes of Health Stroke Scale (NIHSS) ${ }^{13}$ for stroke (-Supplementary Table S3 [available in online version]), and British Medical Research Council Scale (BMRC) for tubercular meningitis ${ }^{14}$ (-Supplementary Table S4 [available in online version]). Severity of patients was also assessed by need for mechanical ventilation (MV). Patients with clinical or radiological suspicion of COVID-19 were tested by real time polymerase chain reaction (RT-PCR) using Invitrogen SuperScript III Platinum One-Step Quantitative Kit (Cat. No.11732088) procured from Indian Council of Medical Research. As per our hospital protocol, all patients requiring emergency or elective in-hospital care were initially kept in separate COVID suspect designated area. Once their COVID-19 RT-PCR reports returned negative, they were shifted to respective specialty wards.

\section{Outcome}

The primary outcome was to study the impact of lockdown during the COVID-19 pandemic on number of patients with neurological emergencies visiting ED per week in pre-lockdown and during lockdown period. Secondary outcomes were disease severity at admission, need for MV, delay in seeking medical attention, reasons for delay in hospitalization, in-hospital mortality, and reason for poor compliance to treatment leading to neurological worsening, if any.

\section{Statistical Analysis}

Continuous and normally distributed variables were represented as mean \pm SD (standard deviation) and compared by using independent $t$-test between "pre-lockdown" and "during lockdown" group, while continuous but nonparametric variables were represented as median (range) and compared using Mann-Whitney U test. Fischer's exact test was used for comparing categorical variables. Multivariate binary logistic regression was used to find independent predictors of in-hospital mortality which included variables with $p<0.1$ on univariate analysis. Structural break in the time series analysis was done by using 
Chow's test. All analyses were done by using Statistical Package for Social Sciences 21 version (SPSS, IBM, Chicago, Illinois, United States) software. A variable with a two-tailed $p$-value of less than 0.05 was considered statistically significant.

\section{Results}

Of 611 neurological cases presenting to ED during the study period, 335 met the inclusion criteria. Overall, 40 patients


therefore based on data of 295 patients. While 244 patients presented in pre-lockdown, 51 presented during lockdown period. Overall, stroke comprised the major bulk of neurological emergencies with 159 (53.4\%) patients, followed by SE with 69 (23.4\%) and tubercular meningitis with 43 (14.6\%) patients. Since there were only two cases of nontubercular meningitis and a single case of never mental disorder during lockdown, they were excluded from further analysis for statistically meaningful results.

\section{Comparison of Demographic Characteristics of the Patients During Pre-Lockdown and Lockdown Period} The sociodemographic characteristics were comparable. The median age of patients was 54 (range $=18-90$ ) years, with 166 (68\%) being males. While age and sex distribution were comparable in both periods, a significant reduction was recorded in number of rural patients with neurological emergencies visiting our ED during lockdown (43.1 vs. $66 \%$, $p=$ 0.001; - Table 1).

\section{Primary Outcome}

Time series analysis revealed significant structural break in number of patients with neurological emergencies visiting ED during lockdown (10.2 visits per week) compared with the pre-lockdown period (22.1 visits per week, $p<0.0001$; - Fig. 2). The percentage reduction in weekly ED visits for stroke, SE and tubercular meningitis (TBM) were 57.02, 53.8, and $36.8 \%$, respectively. However, the proportion of neurological emergencies based on diagnoses were comparable in both periods ( - Table $\mathbf{1}$ ).

\section{Secondary Outcomes}

We analyzed the secondary outcomes including disease severity, delay in hospitalization, poor compliance to treatment for underlying comorbid illnesses, and in-hospital mortality among overall neurological emergencies along with subgroup analysis in stroke, SE, and TBM.

\section{Disease Severity}

Overall, patients presenting during lockdown had more severe disease. Among patients with stroke, the median NIHSS score

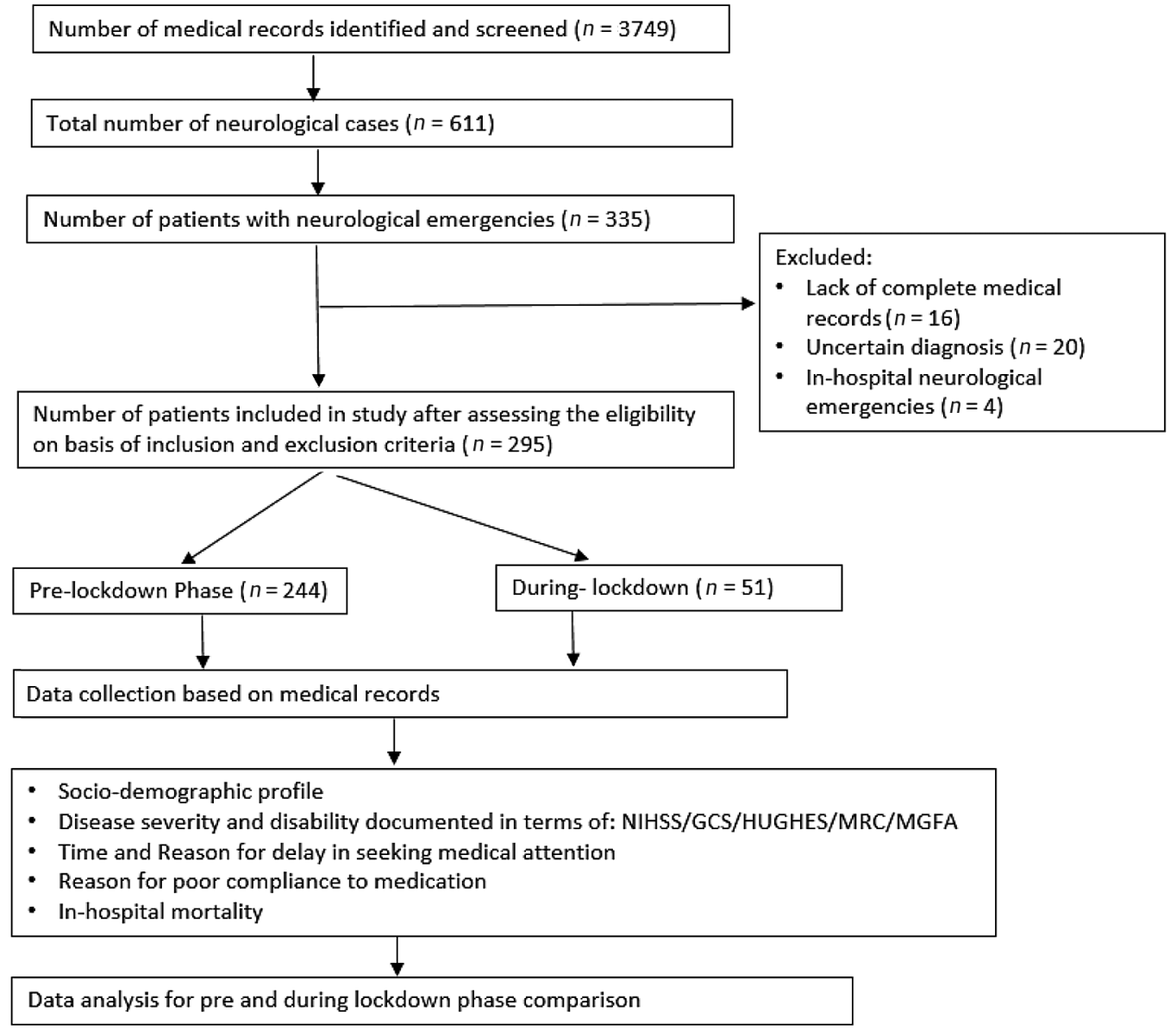

Fig. 1 Flow diagram for this study. 
Table 1 Comparison of the baseline characteristics of the patients between the pre-lockdown and during the lockdown period

\begin{tabular}{|c|c|c|c|c|}
\hline Diagnosis & Parameters & $\begin{array}{l}\text { Pre-lockdown } \\
n=244\end{array}$ & $\begin{array}{l}\text { During lockdown } \\
n=51\end{array}$ & p-Value \\
\hline \multirow[t]{3}{*}{ Total } & Age (y), median (range) & $55(18-90)$ & $53(18-85)$ & 0.44 \\
\hline & Sex (male), $n(\%)$ & $166(68.0)$ & $32(62.7)$ & 0.51 \\
\hline & Patients from rural areas, $n(\%)$ & $161(66.0)$ & $22(43.1)$ & $<0.01$ \\
\hline \multirow[t]{4}{*}{ Stroke } & Cases of stroke, $n(\%)$ & $133(54.5)$ & $26(51.0)$ & 0.65 \\
\hline & Age (y), median (range) & $60(19-90)$ & $62(22-85)$ & 0.36 \\
\hline & Sex (male), $n \%$ & $90(67.7)$ & $18(69.2)$ & 0.87 \\
\hline & Patients from rural areas, $n(\%)$ & $86(64.7)$ & $10(38.5)$ & 0.01 \\
\hline \multirow[t]{4}{*}{ Status epilepticus } & Cases of status epilepticus, $n$ (\%) & $57(23.4)$ & $12(23.5)$ & $>0.99$ \\
\hline & Age (y), median (range) & $45(18-80)$ & $39.5(18-70)$ & 0.15 \\
\hline & Sex (male), $n \%$ & $41(71.9)$ & $6(50.0)$ & 0.13 \\
\hline & Patients from rural areas, $n(\%)$ & $37(64.9)$ & $6(50.0)$ & 0.33 \\
\hline \multirow[t]{4}{*}{ Tubercular meningitis } & Cases of tubercular meningitis, $n$ (\%) & $33(13.5)$ & $10(19.6)$ & 0.32 \\
\hline & Age (y), median (range) & $43(19-76)$ & $21(18-55)$ & 0.02 \\
\hline & Sex (male), $n \%$ & $23(69.7)$ & $7(70.0)$ & 0.98 \\
\hline & Patients from rural areas, $n(\%)$ & $24(72.7)$ & $5(50.0)$ & 0.17 \\
\hline \multirow[t]{4}{*}{ Nontubercular meningitis } & Cases of nontubercular meningitis, $n$ (\%) & $9(3.6)$ & $2(3.9)$ & $>0.99$ \\
\hline & Age (y), median (range) & $60(23-85)$ & $72.5(70-75)$ & 0.25 \\
\hline & Sex (male), $n$ \% & $6(66.7)$ & $1(50.0)$ & 0.65 \\
\hline & Patients from rural areas, $n$ (\%) & $6(66.7)$ & $1(50.0)$ & 0.65 \\
\hline \multirow[t]{4}{*}{ Neuromuscular disease } & Cases of neuromuscular disorders, $n(\%)$ & $12(4.9)$ & $1(2.0)$ & 0.48 \\
\hline & Age (y), median (range) & $37(20-71)$ & $60(60-60)$ & 0.16 \\
\hline & Sex (male), $n \%$ & $6(50.0)$ & $0(0.0)$ & \\
\hline & Patients from rural areas, $n(\%)$ & $8(66.7)$ & $0(0.0)$ & \\
\hline
\end{tabular}

was significantly higher during lockdown compared with pre-lockdown period (median 18 [range $=1-27$ ] vs. median 27 [range $=4-38$ ], $p=0.001$; - Fig. 3). A similar trend was observed in TBM $(p=0.001)$, but not in SE $(p=0.10)$. Significantly higher number of patients required MV $(p<0.0001)$ during lockdown compared with pre-lockdown period ( - Table 2). Similarly, significantly larger proportion of acute stroke patients required decompressive craniotomy during lockdown as compared with pre-lockdown period (8 [6.0\%] vs. 6 [23.1\%], $p<0.0001)$.

\section{Delay in Seeking Medical Attention with Associated Reasons}

Overall, there was a significant delay from the onset of symptoms to hospitalization during lockdown compared with pre-lockdown period (median 7 days [0-56] vs. median 2 days [0-35], $p<0.0001)$. Subgroup analysis revealed significant median delay in hospitalization for stroke, SE, and TBM. Common reasons for delay in seeking health care and hospitalization in pre-lockdown period were financial constraints (25.4\%) and lack of transportation (15.6\%). During lockdown period, poor availability of transportation (43.1\%) and fear of contracting COVID-19 (39.2\%) were the common reasons ( $p<0.0001$; - Table 2).

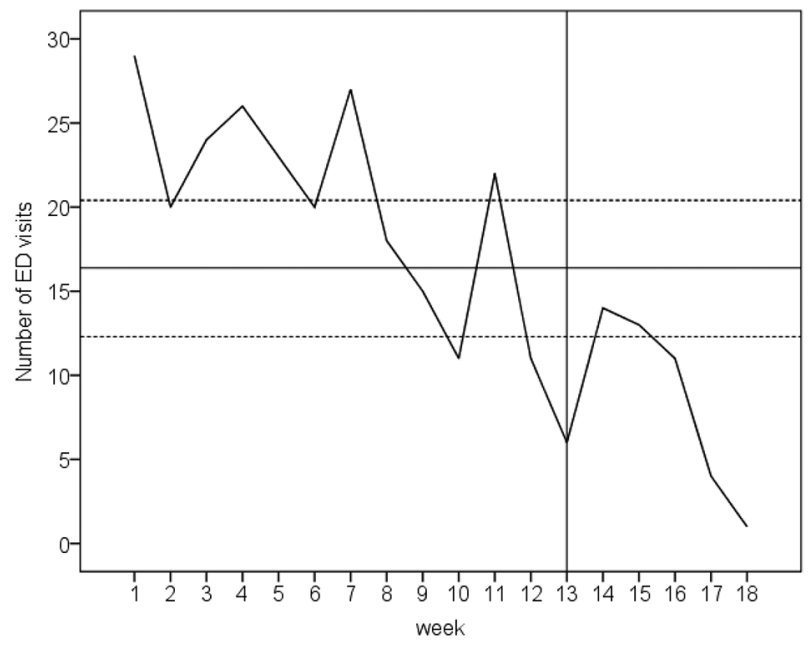

Fig. 2 Number of weekly emergency department visits for neurological emergencies, with mean (solid horizontal line) and two standard deviations (dashed horizontal lines) marked. The vertical solid line indicates (weeks 13-16) correspond to the India's lockdown period. 

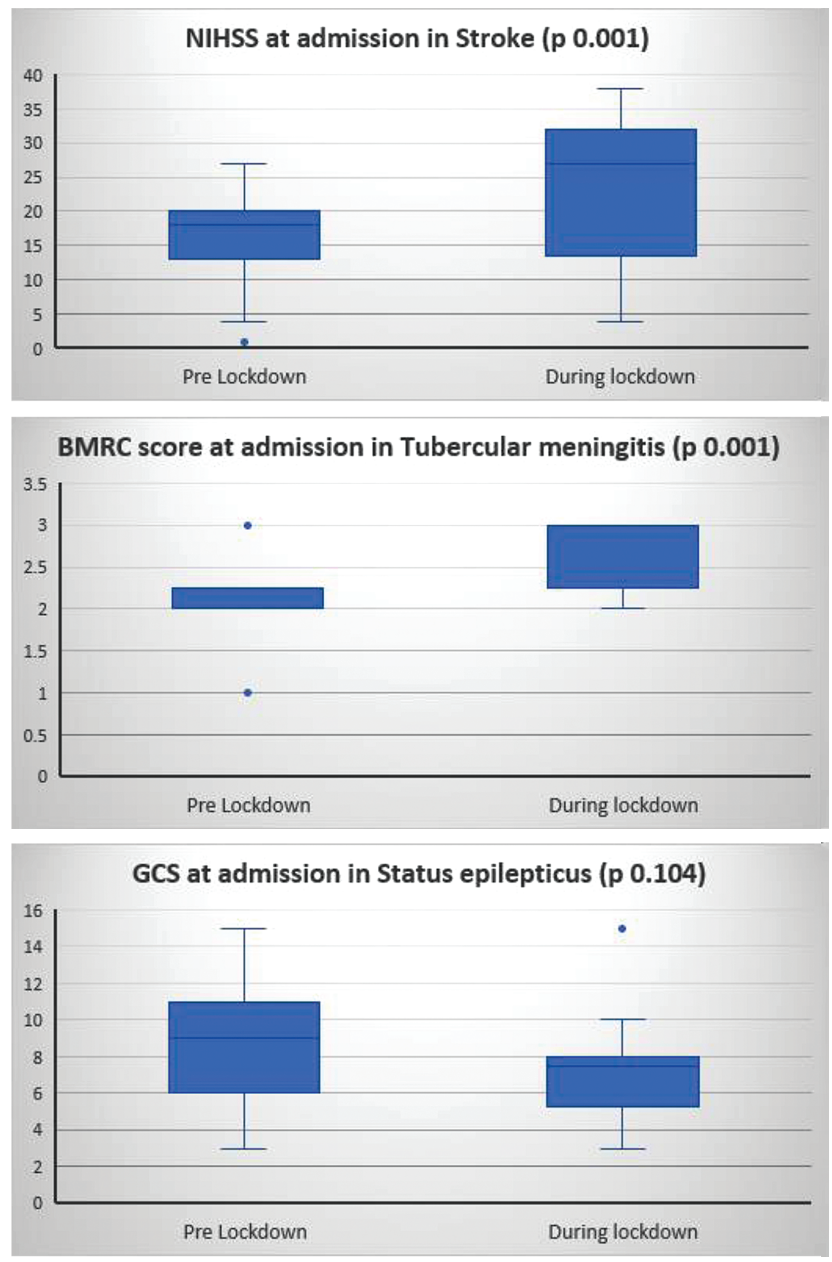

Fig. 3 Box and whisker plot showing effect of lockdown on severity score at admission for various neurological emergencies. BMRC, British Medical Research Council Score for Meningitis; GCS, Glasgow Coma Scale; NIHSS, National Institute of Health Stroke Severity Score.

\section{Reasons for Poor Compliance to Ongoing Treatment for Preexisting Comorbidities}

Overall, poor compliance to treatment for preexisting medical comorbidities increased from $34.4 \%$ in pre-lockdown to $64.7 \%$ during lockdown $(p<0.0001)$, the most common cause being nonavailability of medications $(p<0.0001)$. Other reasons including financial constraints and inaccessibility to LHC were comparable in both periods (-Table 2).

\section{Predictors of In-Hospital Mortality Stratified According to Disease}

Of 295 patients with neurological emergencies, 82 were shifted to nearby tertiary care centers after stabilization in our ED-due to complete bed occupancy-with diversion of health care resources including MV for COVID-19 patients was another reason during lockdown period. The latter included 74 (30.3\%) patients in pre-lockdown and 8 (15.7\%) during lockdown period $(p=0.001)$. Of 213 admitted patients, 35 died with $20(8.2 \%)$ in pre-lockdown and 15 (29.4\%) during lockdown period $(p=0.001)$. Univariate analysis involving 213 patients treated in-hospital revealed "lockdown" along with "nonavailability of LHC," "delay in hospitalization," and "need for MV" being significantly associated with mortality. However, on multivariate analysis only "need for MV" appeared an independent predictor for mortality. Interestingly, subgroup analysis involving stroke patients revealed "lockdown," "nonavailability of LHC," "delay in hospitalization," "NIHSS score at presentation," and "need for MV," all independently influencing mortality. While univariate analysis in SE-yielded "lockdown," "delay in hospitalization," "severity score at presentation," and "need for MV" as significant predictors, only "delay in hospitalization" remained an independent mortality predictor on multivariate analysis. In TBM patients, "severity score at presentation" and "need for MV" were significant predictors on univariate analysis, but "severity score at presentation" remained the only independent predictor of mortality on multivariate analysis (-Table $\mathbf{3}$ ).

\section{Discussion}

Lockdown is an unprecedented situation resorted to by several countries to prevent spread of COVID-19 pandemic. Studies assessing the impact of lockdown on hospital based patient care are lacking. An Italian study evaluating ED visits reported 50\% reduction in minor stroke and transient ischemic attack cases, and $30 \%$ reduction in cases requiring thrombolysis and bridging therapy (combine intravenous thrombolysis and thrombectomy). ${ }^{15}$ Another study reported a $39 \%$ decline in nationwide use of stroke imaging in the United States during early COVID-19 pandemic. ${ }^{16} \mathrm{~A}$ couple of studies analyzing cardiac emergencies reported $40 \%$ reduction in myocardial infarction-related admissions ${ }^{17}$ and $38 \%$ reduction in number of cardiac catheterization laboratory activation. ${ }^{18}$ We observed a $53.8 \%$ reduction in neurological emergencies visiting ED during lockdown. Despite high incidence of stroke in our country (105-152/100,000 persons per year), ${ }^{19}$ nearly $50 \%$ decrement was recorded in acute stroke cases visiting our ED, which is comparable with studies analyzing stroke and cardiac emergencies., 3,20,21

A delay in initiation of appropriate therapy in acute ischemic stroke requiring thrombolysis and SE has been associated with a relatively higher mortality and morbidity. ${ }^{22,23}$ Delay in administration of antitubercular therapy in TBM results in poor outcome. ${ }^{7}$ Thus, avoidance or delay in seeking appropriate medical care may significantly aggravate neurological emergencies. An Italian study analyzing stroke cases reported a longer onset-to-door and door-to-treatment time and a $40 \%$ rise in cases undergoing primary thrombectomies because most stroke cases arrived late and in serious cerebrovascular state. ${ }^{15}$ Another study reported significantly longer delay to intervention (median 10.4 minutes [interquartile range $\{\mathrm{IQR}\}$ : $8.4-13.8$ ] vs. 9.4 minute [7.9-12.6], $p<0.0001)$ and reduction in the proportion of out-of-hospital cardiac arrest [OHCA] patients reaching ED alive [22.8-12.8\% $\{p<0.0001\}]$ ) during the pandemic. $^{24}$ We observed a significant delay of approximately 5 days (2.5 times) from onset of illness to hospitalization during lockdown, with relatively higher severity score at presentation as compared with pre-lockdown period. "Delay in hospitalization" was a significant predictor of poor 
Table 2 Effects of lockdown on various outcome parameters stratified according the neurological emergencies

\begin{tabular}{|c|c|c|c|c|c|c|c|c|c|c|c|c|}
\hline \multirow[t]{2}{*}{ Outcome } & \multicolumn{3}{|c|}{ Total } & \multicolumn{3}{|c|}{ Stroke } & \multicolumn{3}{|c|}{ SE } & \multicolumn{3}{|c|}{ TBM } \\
\hline & $\begin{array}{l}\mathrm{PL} \\
n=244\end{array}$ & $\begin{array}{l}\mathrm{DL} \\
n=51\end{array}$ & $p$-Value & $\begin{array}{l}\mathrm{PL} \\
n=133\end{array}$ & $\begin{array}{l}\text { DL } \\
n=26\end{array}$ & $p$-Value & $\begin{array}{l}\mathrm{PL} \\
n=57\end{array}$ & $\begin{array}{l}\text { DL } \\
n=12\end{array}$ & $p$-Value & $\begin{array}{l}P L \\
n=33\end{array}$ & $\begin{array}{l}\mathrm{DL} \\
n=10\end{array}$ & $p$-Value \\
\hline $\begin{array}{l}\text { Primary } \\
\text { outcome } \\
\text { ED visits per } \\
\text { week }\end{array}$ & 22.1 & 10.2 & $<0.01$ & 12.1 & 5.2 & $<0.0001$ & 5.2 & 2.4 & 0.04 & 3.8 & 2.4 & 0.21 \\
\hline \multicolumn{13}{|c|}{ Secondary outcomes } \\
\hline $\begin{array}{l}\text { Severity, }{ }^{\mathrm{a}} \\
\text { median (range) }\end{array}$ & & & & $\begin{array}{l}18 \\
(1-27)\end{array}$ & $\begin{array}{l}27 \\
(4-38)\end{array}$ & 0.001 & $\begin{array}{l}9 \\
(3-15)\end{array}$ & $\begin{array}{l}7.5 \\
(3-15)\end{array}$ & 0.10 & $\begin{array}{l}2 \\
(1-3)\end{array}$ & $\begin{array}{l}3 \\
(1-3)\end{array}$ & 0.001 \\
\hline $\begin{array}{l}\text { Need for MV, } \\
n(\%)\end{array}$ & $\begin{array}{l}67 \\
(27.5)\end{array}$ & $\begin{array}{l}28 \\
(54.9)\end{array}$ & $<0.0001$ & $\begin{array}{l}15 \\
(11.3)\end{array}$ & $\begin{array}{l}17 \\
(65.4)\end{array}$ & $<0.0001$ & $\begin{array}{l}31 \\
(54.4)\end{array}$ & $\begin{array}{l}9 \\
(75)\end{array}$ & 0.22 & $\begin{array}{l}12 \\
(36.4)\end{array}$ & $\begin{array}{l}2 \\
(20.0)\end{array}$ & 0.46 \\
\hline $\begin{array}{l}\mathrm{DH} \text { (days), } \\
\text { median (range) }\end{array}$ & $\begin{array}{l}2 \\
(0-35)\end{array}$ & $\begin{array}{l}7 \\
(0-56)\end{array}$ & $<0.0001$ & $\begin{array}{l}2 \\
(0-10)\end{array}$ & $\begin{array}{l}7 \\
(0-10)\end{array}$ & $<0.0001$ & $\begin{array}{l}2 \\
(1-4)\end{array}$ & $\begin{array}{l}2.5 \\
(1-4)\end{array}$ & $<0.0001$ & $\begin{array}{l}12 \\
(2-35)\end{array}$ & $\begin{array}{l}30 \\
(12- \\
56)\end{array}$ & $<0.0001$ \\
\hline \multicolumn{13}{|c|}{ Reasons for delay, $n(\%)$} \\
\hline $\begin{array}{l}\text { Lack of } \\
\text { transport }\end{array}$ & $\begin{array}{l}38 \\
(15.6)\end{array}$ & $\begin{array}{l}22 \\
(43.1)\end{array}$ & $<0.0001$ & $\begin{array}{l}16 \\
(12.0)\end{array}$ & $\begin{array}{l}12 \\
(46.2)\end{array}$ & $<0.0001$ & $\begin{array}{l}13 \\
(22.8)\end{array}$ & $5(41.7)$ & 0.28 & $\begin{array}{l}5 \\
(15.2)\end{array}$ & $\begin{array}{l}5 \\
(50.0) \\
\end{array}$ & 0.04 \\
\hline $\begin{array}{l}\text { Fear of } \\
\text { COVID-19 }\end{array}$ & $2(0.8)$ & $\begin{array}{l}20 \\
(39.2)\end{array}$ & $<0.0001$ & $1(0.8)$ & $8(30.8)$ & $<0.0001$ & $0(0.0)$ & $5(41.7)$ & & $0(0.0)$ & $\begin{array}{l}5 \\
(50.0)\end{array}$ & \\
\hline Financial issues & $\begin{array}{l}62 \\
(25.4)\end{array}$ & $\begin{array}{l}6 \\
(11.8)\end{array}$ & 0.04 & $\begin{array}{l}30 \\
(22.6) \\
\end{array}$ & $4(15.4)$ & 0.60 & $\begin{array}{l}15 \\
(26.3) \\
\end{array}$ & $1(8.3)$ & 0.27 & $\begin{array}{l}12 \\
(36.4)\end{array}$ & $0(0.0)$ & \\
\hline $\begin{array}{l}\text { Poor compli- } \\
\text { ance, } n(\%)\end{array}$ & $\begin{array}{l}84 \\
(34.4)\end{array}$ & $\begin{array}{l}33 \\
(64.7)\end{array}$ & $<0.0001$ & $\begin{array}{l}56 \\
(42.1)\end{array}$ & $\begin{array}{l}20 \\
(76.9)\end{array}$ & 0.004 & $\begin{array}{l}15 \\
(26.3)\end{array}$ & $\begin{array}{l}9 \\
(75.0)\end{array}$ & 0.002 & $\begin{array}{l}3 \\
(9.09)\end{array}$ & $\begin{array}{l}2 \\
(20.0)\end{array}$ & 0.57 \\
\hline \multicolumn{13}{|c|}{ Reasons for poor compliance, $n(\%)$} \\
\hline $\begin{array}{l}\text { Nonavailability } \\
\text { of drugs }\end{array}$ & $4(1.6)$ & $\begin{array}{l}14 \\
(27.5)\end{array}$ & $<0.0001$ & $1(0.8)$ & $8(30.8)$ & $<0.001$ & $1(1.8)$ & $5(41.7)$ & 0.004 & $1(3.0)$ & $0(0.0)$ & \\
\hline Financial issues & $\begin{array}{l}44 \\
(18.0)\end{array}$ & $\begin{array}{l}10 \\
(19.6)\end{array}$ & 0.84 & $\begin{array}{l}30 \\
(22.6)\end{array}$ & $6(23.1)$ & 0.81 & $\begin{array}{l}7 \\
(12.3)\end{array}$ & $1(8.3)$ & $>0.99$ & $1(3.0)$ & $\begin{array}{l}2 \\
(20.0)\end{array}$ & 0.13 \\
\hline $\begin{array}{l}\text { Inaccessibility } \\
\text { to LHC }\end{array}$ & $\begin{array}{l}36 \\
(14.8)\end{array}$ & $\begin{array}{l}9 \\
(17.6)\end{array}$ & 0.67 & $\begin{array}{l}25 \\
(18.8)\end{array}$ & $6(23.1)$ & 0.60 & $\begin{array}{l}7 \\
(12.3)\end{array}$ & $3(25.0)$ & 0.36 & $1(3.0)$ & $0(0.0)$ & \\
\hline
\end{tabular}

Abbreviations: BMRC, British Medical Research Council; COVID-19, coronavirus disease 2019; DL, during lockdown; DH, delay in hospitalization; ED, emergency department; GCS, Glasgow Coma Scale; LHC, local health care; MV, mechanical ventilation; NIHSS, National Institutes of Health Stroke Scale; PL, pre-lockdown; SE, status epilepticus; TBM, tubercular meningitis.

Note: Total cases of neurological emergencies included stroke, meningitis, status epilepticus, and neuromuscular disorders. However, subgroup analysis for nontubercular meningitis and neuromuscular disorders was not done due to small sample size.

aFor severity scoring: NIHSS for stroke, GCS at admission for seizure, and BMRC for tubercular meningitis.

outcome for neurological emergencies on univariate analysis, but appeared an independent predictor of poor outcome in stroke and SE on multivariate analysis. A one-and-a-half times rise in delay in hospitalization in TBM was observed. Although it appeared nonsignificant, probably related to the small sample size, it likely contributed to "severity at presentation," an independent predictor of poor outcome.

During pandemic, several factors might have influenced ED visits, including Government regulations and strict instructions to stay at home, fear of contracting COVID-19 in hospital, financial constraints, restricted transportation facilities during lockdown, and poor availability of LHC services resulting in failure to recognize impending neurological emergency in a patient. ${ }^{18,25}$ Although lack of transport facilities and financial constraints were major reasons for delay in hospitalization in pre-lockdown, the former along with fear of contracting COVID-19 were the significant reasons for the same during lockdown, in our study. Although we lack data on the socioeconomic status of our patients, financial constraints as a reason for a longer delay in hospitalization was significantly common in pre-lockdown period. A near complete halt in majority of industrial work during lockdown resulted in a significant rise in unemployment, with laborers and daily wage workers quickly running out of their meagre reserve. ${ }^{26}$ Possibly, a significant proportion of these patients might have failed to reach hospitals, especially when transport facilities were already restricted during lockdown.

India is a developing country, with $63 \%$ of its population residing in villages. ${ }^{27}$ Although public transport facilities are cheaper, it is mostly lacking ${ }^{28}$ and even population from lower socioeconomic strata have to spend their valuable earnings on private transport facilities for commuting, even during medical emergencies. ${ }^{29}$ Indian villages mostly consist of population from lower socioeconomic strata, and it was not unlikely to observe a significant decline in rural patients visiting ED during lockdown period $(p=0.004)$, although rest of the demographic profile including age and sex remained comparable in both periods, similar to the observation reported in a study analyzing OHCA in France. ${ }^{24}$ 
Effect of COVID-19 on Non-COVID Neurological Emergencies Thar et al.

467

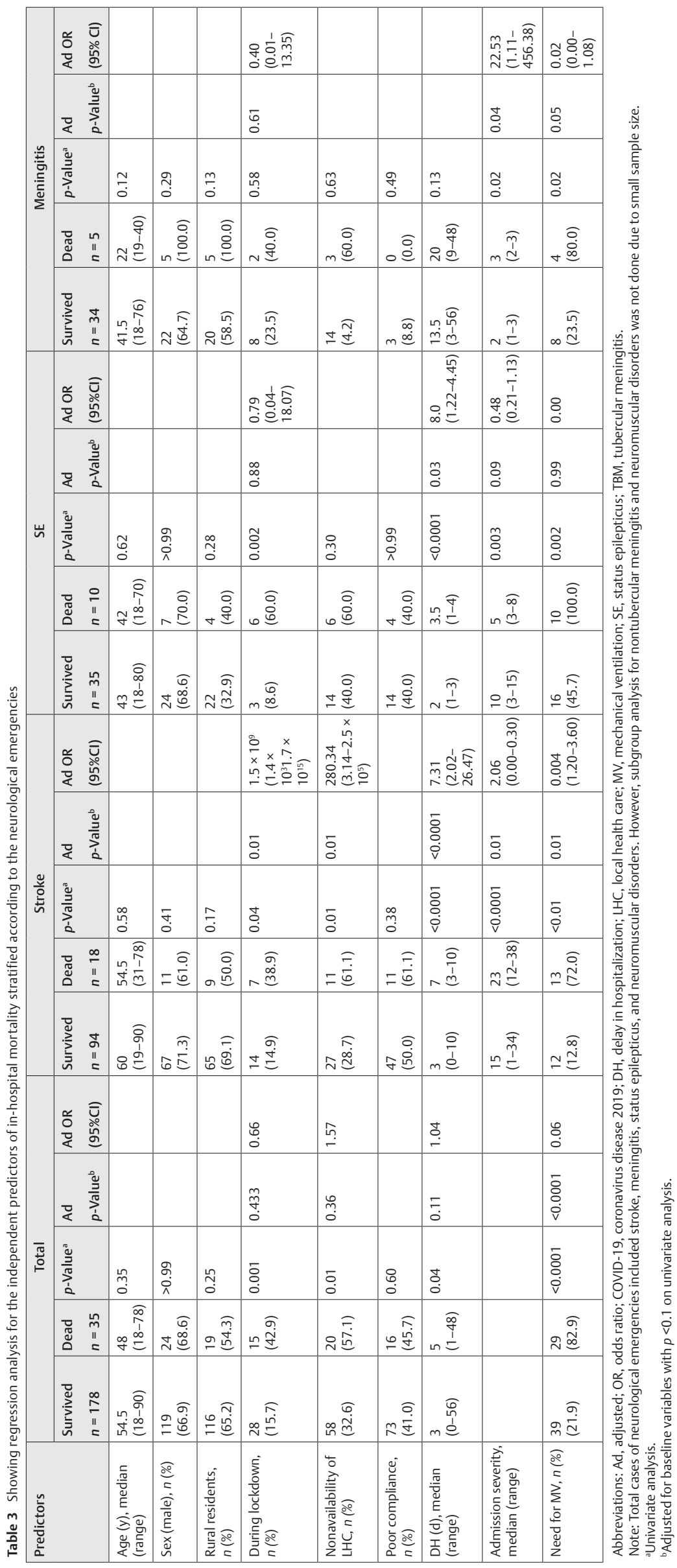

Journal of Neurosciences in Rural Practice Vol. 12 No. 3/2021 $\quad$ @ 2021. Association for Helping Neurosurgical Sick People. 
Poor compliance to ongoing treatment for preexisting comorbidities appeared a major reason of neurological worsening and ED visit, with poor availability of medications including antihypertensive (27.8\%), antidiabetic (11.1\%), antiplatelets (11.1\%), and antiepileptics (33.3\%) during lockdown being the most common influencing factors. It assumes significance for neurological emergencies, especially stroke and SE. It highlights the importance of maintenance of pharmaceutical supply chain, even in unprecedented conditions including lockdown as disruption may significantly affect patients with chronic illnesses, well controlled on medications, including those with hypertension, diabetes, chronic stroke, and epilepsy.

In addition to lockdown, delay in hospitalization, NIHSS at presentation and need for MV, poor availability of LHC services influenced the outcome in stroke patients. LHC services provide patients immediate medical attention and urgent referral to a tertiary care center for appropriate specialized therapy, if needed. Adjustment in social norms and health care system during lockdown had affected the delivery of services by local medical facilities in nonurban areas leading to delay in seeking specialized care. ${ }^{30}$

Our study reveals a significant decline in non-COVID neurological emergencies visiting ED, with possibly a high non-COVID morbidity and mortality going unnoticed, especially in rural population during COVID-19 pandemic. This assumes importance as the role of a strict lockdown in protecting old and frail people has become unclear. ${ }^{31}$ Thus, maintenance of continuous health care access and pharmaceutical supply chain up to the grass root levels may improve outcomes. Retrospective design, single-center study, short study period, and small sample size are the major limitations of our study. However, the outcome parameters were sufficiently robust and the results are in keeping with those reported from Europe and the United States. A multicenter study is desirable to confirm our findings. We have excluded in-hospital non-neurology patients developing neurological emergencies in the due course to maintain homogeneity of the data as we mainly focused on primary neurological emergencies visiting our ED.

\section{Conclusion}

COVID-19 pandemic and associated policies including lockdown resulted in marked reduction in number of neurological emergencies seeking medical attention. Neurological emergencies presenting to ED during lockdown had more severe disease, and there was a significant delay from the onset of symptoms to hospitalization. Lockdown was independently associated with poor outcome at discharge, especially in patients with stroke Maintenance of continuous health care access and pharmaceutical supply chain concerning non-COVID illnesses is essential.

\section{Authors' Contributions}

D.N. and G.M. supported in data collection, statistics, and writing the first manuscript. M.K. and A.T. helped in statistics and review and critique. N.K. performed conception and helped in review and critique. V.J. carried out data collection and helped in review and critique.

\section{Funding}

None.

\section{Conflict of Interest}

None declared.

\section{References}

1 Cucinotta D, Vanelli M. WHO declares COVID-19 a pandemic. Acta Biomed 2020;91(1):157-160

2 Biswas A, Bhattacharjee U, Chakrabarti AK, Tewari DN, Banu H, DuttaS. emergence of novel coronavirus and COVID-19: whether to stay or die out? Crit Rev Microbiol 2020;46(2):182-193

3 Sylaja PN, Srivastava MVP, Shah S, et al. The SARS-CoV-2/ COVID-19 pandemic and challenges in stroke care in India. Ann N Y Acad Sci 2020;1473(1):3-10

4 Sacco RL, Kasner SE, Broderick JP, et al; American Heart Association Stroke Council, Council on Cardiovascular Surgery and Anesthesia Council on Cardiovascular Radiology and Intervention Council on Cardiovascular and Stroke Nursing Council on Epidemiology and Prevention Council on Peripheral Vascular Disease Council on Nutrition, Physical Activity and Metabolism. An updated definition of stroke for the 21st century: a statement for healthcare professionals from the American Heart Association/American Stroke Association. Stroke 2013;44(7):2064-2089

5 Trinka E, Cock H, Hesdorffer D, et al. A definition and classification of status epilepticus: report of the ILAE task force on classification of status epilepticus. Epilepsia 2015;56(10):1515-1523

6 Karen L, Roos, Kenneth L. Tyler. Acute meningitis. In: J. Larry Jameson, Anthony S. Fauci, Dennis L. Kasper, Stephen L. Hauser, Dan L. Longo, Joseph Loscalzo, eds. Harrisons Principles Of Internal Medicine. 20th ed. New York: McGraw-Hill Education; 2018:998-1006

7 Marais S, Thwaites G, Schoeman JF, et al. Tuberculous meningitis: a uniform case definition for use in clinical research. Lancet Infect Dis 2010;10(11):803-812

8 Asbury AK, Cornblath DR. Assessment of current diagnostic criteria for Guillain-Barré syndrome. Ann Neurol 1990;27(Suppl):S21-S24

9 Uncini A, Yuki N. Electrophysiologic and immunopathologic correlates in Guillain-Barré syndrome subtypes. Expert Rev Neurother 2009;9(6):869-884

10 Gilhus NE, Verschuuren JJ. Myasthenia gravis: subgroup classification and therapeutic strategies. Lancet Neurol 2015;14(10):1023-1036

11 Hughes RA, Newsom-Davis JM, Perkin GD, Pierce JM. Controlled trial prednisolone in acute polyneuropathy. Lancet 1978;2(8093):750-753

12 Jayam Trouth A, Dabi A, Solieman N, Kurukumbi M, Kalyanam J. Myasthenia gravis: a review. Autoimmune Dis 2012;2012:874680

13 Hage V. The NIH stroke scale: a window into neurological status. NurseCom Nursing Spectrum 2011;24(15):44-49

14 British Medical Research Council. Streptomycin treatment of tuberculous meningitis. Lancet 1948;1(6503):582-596

15 Baracchini C, Pieroni A, Viaro F, et al. Acute stroke management pathway during coronavirus-19 pandemic. Neurol Sci 2020;41(5):1003-1005

16 Kansagra AP, Goyal MS, Hamilton S, Albers GW. Collateral effect of Covid-19 on stroke evaluation in the United States. N Engl J Med 2020;383(4):400-401

17 Metzler B, Siostrzonek P, Binder RK, Bauer A, Reinstadler SJ Decline of acute coronary syndrome admissions in Austria since the outbreak of COVID-19: the pandemic response causes cardiac collateral damage. Eur Heart J 2020;41(19):1852-1853 
18 Garcia S, Albaghdadi MS, Meraj PM, et al. Reduction in ST-segment elevation cardiac catheterization laboratory activations in the United States during COVID-19 pandemic. J Am Coll Cardiol 2020;75(22):2871-2872

19 Kamalakannan S, Gudlavalleti ASV, Gudlavalleti VSM, Goenka S, Kuper H. Incidence \& prevalence of stroke in India: a systematic review. Indian J Med Res 2017;146(2):175-185

20 Siegler JE, Heslin ME, Thau L, Smith A, Jovin TG. Falling stroke rates during COVID-19 pandemic at a comprehensive stroke center. J Stroke Cerebrovasc Dis 2020;29(8):104953

21 Diegoli H, Magalhães PS, Martins SC, et al. Decrease in hospital admissions for transient ischemic attack, mild, and moderate stroke during the COVID-19 era. Stroke 2020. Doi:10.1161/ STROKEAHA.120.030481

22 Emberson J, Lees KR, Lyden P, et al; Stroke Thrombolysis Trialists' Collaborative Group. Effect of treatment delay, age, and stroke severity on the effects of intravenous thrombolysis with alteplase for acute ischaemic stroke: a meta-analysis of individual patient data from randomised trials. Lancet 2014;384(9958):1929-1935

23 Gaínza-Lein M, Fernández IS, Ulate-Campos A, Loddenkemper T, Ostendorf AP. Timing in the treatment of status epilepticus: from basics to the clinic. Seizure 2019;68:22-30

24 Marijon E, Karam N, Jost D, et al. Out-of-hospital cardiac arrest during the COVID-19 pandemic in Paris, France: a population-based, observational study. Lancet Public Health 2020;5(8):e437-e443

25 Masroor S. Collateral damage of COVID-19 pandemic: delayed medical care. J Card Surg 2020;35(6):1345-1347

26 Rodela TT, Tasnim S, Mazumder H, Faizah F, Sultana A, Hossain MM. Economic impacts of coronavirus disease (COVID-19) in developing countries. Center for Open Science2020;Doi:10.31235/osf.io/wygpk

27 Kumar P, Kumar R. Rural health scenario - role of family medicine: academy of family physicians of India position paper. J Family Med Prim Care 2018;7(6):1157-1162

28 Pucher J, Korattyswaroopam N, Ittyerah N. The crisis of public transport in India: overwhelming needs but limited resources. J Public Transp 2004;7(4):1

29 Pandian JD, Kalra G, Jaison A, et al. Factors delaying admission to a hospital-based stroke unit in India. J Stroke Cerebrovasc Dis 2006;15(3):81-87

30 Deepthi R, Mendagudli RR, Kundapur R, Modi B. Primary health care and COVID-19 pandemic. International Journal of Health Systems and Implementation Research 2020;4(1):20-29

31 Johnson HC, Gossner CM, Colzani E, et al. Potential scenarios for the progression of a COVID-19 epidemic in the European Union and the European Economic Area, March 2020. Euro Surveill 2020;25(9):2000202 